\title{
Urban infrastructure mines: on the economic and environmental motives of cable recovery from subsurface power grids
}

Joakim Krook, Niclas Svensson and Björn Wallsten

\author{
Linköping University Post Print
}

Tweet

N.B.: When citing this work, cite the original article.

Original Publication:

Joakim Krook, Niclas Svensson and Björn Wallsten, Urban infrastructure mines: on the economic and environmental motives of cable recovery from subsurface power grids, 2015, Journal of Cleaner Production, (104), 353-363.

http://dx.doi.org/10.1016/j.jclepro.2015.05.071

Copyright: Elsevier

http://www.elsevier.com/

Postprint available at: Linköping University Electronic Press

http://urn.kb.se/resolve?urn=urn:nbn:se:liu:diva-120436 


\title{
Urban Infrastructure Mines: on the economic and environmental motives of cable recovery from subsurface power grids
}

\author{
Joakim Krook*, Niclas Svensson, Björn Wallsten \\ Department of Management and Engineering, Environmental Technology and Management, \\ Linköping University, SE-581 83 Linköping, Sweden \\ *Corresponding author. Tel.: +46 132889 03; fax: +4613281399. \\ E-mail address: joakim.krook@liu.se
}

\begin{abstract}
Subsurface power grids constitute one of the largest copper stocks in many industrialized cities. Over time, parts and zones of these systems have been continuously disconnected and abandoned, resulting in the emergence of urban infrastructure ores. This study aims to assess how current conditions and practices influence economic and environmental motives of cable recovery from such power grids. By applying an infrastructure manager's perspective and evaluating 16 scenarios involving different extraction technologies and procedures, surface materials, urban locations and types of cables, we identify key areas where solutions or changes to increase incentives for cable recovery are needed.
\end{abstract}

The assessed scenarios display significantly different cable extraction costs, where excavation in city centers with asphalt or cobblestone pavements generates the highest costs while greenbelts offer the best conditions. In most cases, cable revenues are not even close to outweighing the extraction costs. This is especially true for paper-coated cables or cables with aluminum conductors, for which the revenues are much lower than for plastic-insulated copper cables. Although economic conditions could be improved by integrating cable recovery to regular system upgrade projects or by applying non-digging technologies, clear incentives rely on the cable in question being especially valuable. Most of the cable recovery scenarios display environmental motives in terms of net savings in GHG emissions due to metal recycling. In contrast to the economic results, recycling of aluminum power cables is here more awarding than that of corresponding copper cables.

We conclude that under current conditions urban mining does not make economic sense to infrastructure managers unless it is integrated as an added value to system upgrade projects. Apart from such re-arrangements in infrastructure provision, several other practice-related changes to cut cable extraction costs are possibly within reach for the managers. Still, an economically motivated practice relies on several external performance drivers such as market diffusion of non-digging technologies, improved cable recycling processes, and increased scrap metal prices. Our conclusion that the arguments for urban mining are currently more environmental than financial, points towards changed perspectives where such activities are seen as a way for infrastructure managers to contribute to societal goals such as climate change mitigation and reduced mineral resource dependence.

Key words: Urban mining, metals recycling, private economics, life cycle assessment, actor perspective 


\section{Introduction}

A key challenge of sustainability is that mankind has to increasingly rely on recycling of materials, not only for environmental reasons but for the political and economic implications of universal changes such as primary resource scarcity as well. From a mass flow perspective, such a challenge is inherently problematic given that the annual societal discards often are too small to cover any significant share of our steadily increasing appetite for natural resources (Baccini and Brunner, 2012). On the other hand, when it comes to strategically important base metals almost half of the amounts extracted to date are no longer in use (Spatari et al., 2005; Müller et al., 2006). These previously employed materials can be found either in different waste deposits or in obsolete products, buildings and infrastructure left behind in the built environment. Exploiting these often forgotten technospheric stocks, sometimes referred to as urban and landfill mining, could thus provide the recycling industry with significant amounts of additional raw materials, making it possible for this sector to grow beyond the physical limits of annual waste streams and become a more important supplier (Bergbäck and Lohm, 1997; Krook et al., 2011; Krook et al., 2012).

In Sweden, it has been estimated that the amount of accumulated copper in power and telecom grids exceeds 1.5 million metric tons, making such infrastructure one of the largest stocks in the technosphere (Wendell, 2005; Sörme et al., 2001; Krook and Baas, 2013). The majority of these quantities of copper are located in urban areas - a phenomenon which is also confirmed by international studies demonstrating concentrations of metal up to a hundred times higher in urban than in rural areas (van Beers and Graedel, 2007). One contributing factor to this high density in metal stocks is that subsurface infrastructures for power, telecom, gas, water supply and so on consist of massive networks of cables and pipes rich in base metals such as iron, copper and aluminum (Wendell, 2005; Wallsten et al., 2013a). Such infrastructure systems permeate industrialized cities in the northern hemisphere, and as such are literally embedded in the urban fabric (Graham, 2000). While most of this infrastructure is still operational, parts and zones of these networks have been continuously disconnected during maintenance and system upgrading and thereafter left behind in the "invisible" urban landscape. Over the decades, this disconnect-and-leave-behind logic of infrastructure provision has resulted in the accumulation of significant subsurface urban ores - obsolete metal stocks accessible for urban mining initiatives (Krook and Baas, 2013).

Many of the still operational, first-generation infrastructure networks are old and have already surpassed their lifetime expectancy. In order to secure their essential functions, huge investments in replacements and system upgrading will be required in the years to come. Knowing that the very limited urban infrastructure mining that currently occurs only does so in relation to system maintenance and repair (Wallsten et al., 2013b), suggests a potential for integrating urban mining initiatives with such future system upgrades.

So far, urban mining research on disconnected subsurface infrastructure has mainly focused on analyzing the occurrence, quantities and spatial location of metals stocks (Krook et al., 2011; Wallsten et al., 2013a). Although it is concluded that the established disconnect-andleave-behind logic originates from a combination of technical, organizational, cultural and regulatory conditions (Wallsten et al., 2013b), the most straightforward reason for why derelict cables remain in the soil is the high costs for urban excavation work (Krook et al., 2011). However, the economics of such urban mining projects have not yet been thoroughly studied and are thus largely uncertain. In fact, there are many economic aspects that may or may not turn out to be significant depending on exactly where, how and for what reasons projects are realized. In principle, the same is true for the environmental impacts of this type 
of urban mining where the type of cable(s) to be extracted, street paving, applied technologies, procedures for site restoration, accessible markets for recycling and transportation needs are all examples of potentially influencing factors. Identifying the potential and challenges related to urban infrastructure mining thus calls for a system approach reliant on a wide range of project-specific factors and the inclusion of both economic and environmental motives.

\subsection{Aim}

The aim of this article is to assess how current technical, organizational, regulatory and market conditions and practices influence economic and environmental motives of cable recovery from disconnected urban power grids in Sweden. This is engaged with in order to illuminate under what site-specific factors and in which project settings urban mining might be a potentially economically viable activity for the individual actor as well as environmentally justified for society at large. Rather than drawing conclusions about the net economic and environmental performance of specific urban mining projects, our intention here is to learn more about the relative importance of different influencing factors and conditions and thereby pinpoint key topics for future knowledge, technology development or societal rearrangements.

\section{Analytical approach and method}

This article applies an actor perspective, implying that the focus is on the acting space of actors involved in the process of inquiry while the external framework (i.e. current policy, regulatory and market conditions) in which the actors' activities take place is assumed to remain unaltered. Our emphasis is thus to break down the current economic and environmental (dis-)incentives of urban mining for the local infrastructure manager, rather than assessing impacts of different external changes in waste management and recycling markets, raw material prices and national policies regarding, e.g., resource conservation or infrastructure regulation. The plain argument for choosing such an actor's point of view is that urban mining will most likely not happen if it cannot be economically or environmentally motivated for the local infrastructure manager.

This article is an urban mining case-study of the city of Linköping ${ }^{1}$. Our approach is to assess the heterogeneous complexity found in the details of this specific case as a way to initiate knowledge and theory development within this emerging area. This means that the results are primarily applicable to the studied case, but the fact that infrastructure provision is arranged in the same way in many other domestic cities (EBR, 2013) implies the relevance and generalizability to Swedish conditions and practices. Although the overall findings from this case-study plausibly also are of relevance for urban infrastructure mining in other cities throughout the world, we believe that any such generalization must go with a thorough analysis of the actual conditions and practices of the specific case in question. Thus, in order to accurately extend the generalizability of our results beyond Swedish boarders and conditions, comparative studies from other parts of the world are strongly encouraged.

\subsection{Developing scenarios for evaluation of urban infrastructure mining}

In both the economic and environmental assessment, our ambition has been to define cable extraction scenarios describing the best as well as worst-case scenarios. This enables us to display interval ranges in which possible real-world projects can be located as well as compared. To these intervals, representing different cost and environmental impact profiles, we add break-even lines indicating revenues and avoided environmental burdens that are

\footnotetext{
${ }^{1}$ Linköping is a medium-size Swedish city with approximately 140,000 inhabitants.
} 
obtained by recycling different power cables. Such an analytical approach makes it possible to identify and discuss changes required for a project to make either economic or environmental sense.

\subsubsection{Main variables influencing costs and environmental impacts of cable extraction} Even if an urban infrastructure mining project is limited both in time and space, it can nevertheless be done in many different ways. To encapsulate this diversity, the study was performed through the development of 16 cable extraction scenarios that rely on four sets of main variables: extraction technology, geographic location, type of project, and surface material (Figure 1). The overarching importance of these variables was identified through consultations with two experienced infrastructure managers, previous research (e.g. Tighe et al., 2002; Krook et al., 2011; Matthews et al., 2015) and reviews of economic budgets of three real-life infrastructure projects in Linköping.

In order to test how technological aspects affect the costs and environmental impact of cable extraction, two distinguishable technologies were compared in the scenarios: conventional digging and Kabel-X. The latter involves a non-digging technology that mechanically pulls out only the metal conductor of an obsolete cable (Pochhacker and Furman, 2012). Perhaps the most apparent reasons for why Kabel-X is an interesting technology for our case, is that it requires far less excavation work and traffic re-routing compared to traditional procedures, making it potentially beneficial both from an economic and environmental perspective. At present, Kabel-X is in an early development phase but has been shown to work satisfactorily for some plastic insulated power cables in pilot study testing procedures (Pochhacker and Furman, 2012). While there still is a series of remaining uncertainties regarding the applicability of the technology on power cables, we wanted to develop the scenarios to reach an understanding of what might be achieved once it is fully operational and customary practice in infrastructure provision.

\section{Figure 1}

In the scenarios, the two technologies were tested in different geographic locations: the city center and the rest of the surrounding city area (from now on referred to as "non-city center"). There are two reasons for why our scenarios delineate between these two. First, the space for storing excavated material is in shorter supply in city centers than non-city center areas.

Because of this, all earth material dug up in city centers is typically transported to the nearest landfill site where it is used as landfill construction material while the refilling of the cable trench is done with purchased virgin earth materials (Jönsson, 2014). For the non-city center areas on the other hand, nearby space for temporary storage is more likely to be found and so transportation to a landfill is only required for about half of the unearthed material. In such locations, the cable trench is thus refilled with a half-and-half mix of new ballast material and temporary stored masses. Second, traffic re-routing and shut-offs are more expensive in city centers, since such places involve a higher amount of traffic, local businesses, offices, bus routes, cross streets and trunk lines whose operations must be ensured during the course of a project. Although considerable variations occur between projects, Swedish city center projects are typically about $30 \%$ more expensive than other infrastructure projects (EBR, 2013).

The third set of main variables captures how cable recovery can be done with different pretenses. This can both be the sole reason for why a project is conducted and be integrated as an added part to a regular infrastructure system upgrade project (from now on referred to as integrated project), in which a malfunctioning power cable is to be replaced with a new one. 
Such different project settings are essential for the assessment of the scenarios ${ }^{2}$ since they influence which costs, revenues and environmental impact should be allocated to the cable recovery part (cf. Krook et al., 2011).

Lastly, cables in city power grids can be located in different underground locations, which mean that the surface material that needs to be removed and restored can differ. In the streetscape, power cables are virtually always situated in the sidewalks and not in the center of the street used by motor vehicles, as is the case for other subsurface infrastructure such as water supply and district heating pipes (Swedish standard, 2008). Different surface materials represent the fourth main scenario variable and are chosen to vary from the rather cheap and easily handled grass (i.e. cables located in city parks or greenbelts) to the more costly asphalt or labor-intensive cobblestones representing common sidewalk pavements (cf. EBR, 2013). Furthermore and according to current practices, it is often required for anyone digging in Swedish urban streetscapes paved with asphalt, that the entire width of the street's pavement is removed and re-paved, rather than just the section needed for the maintenance trench (Jönsson, 2014). The underlying reason for this is to prevent streets from becoming patchwork quilts of different aged asphalt shreds, for reasons related both to street surface quality and aesthetic perspectives. Also for punctiform shafts, e.g. used by non-digging technologies such as Kabel-X, the whole width of the street needs to be re-paved but only in the immediate proximity of the shafts. This practice is motivated by the significant costs and disturbances that re-paving the whole width and length of the street only due to such scattered and minor intrusions would generate (Jönsson, 2014).

\subsubsection{Selection of power cables for revenues and environmental impacts of recycling}

In the scenarios, we have included four main types of cables which are common in Swedish power grids, especially when it comes to disconnected parts (Andersson, 2013). These cables involve different metal conductors, dimensions and insulation materials (Table 1), factors that directly influence the revenues and environmental impacts of recycling processes.

Historically, copper $(\mathrm{Cu})$ has totally dominated the market of power conductors, but since the 1970s the use of aluminum (Al) conductors has gradually increased, particularly in highvoltage applications (Andersson, 2013). However, most of the disconnected cables in Swedish power grids involve paper-coated copper conductors of varying dimensions.

\section{Table 1}

The revenues that can be obtained from selling power cables are directly related to their dimension and type of metal conductor, i.e., their content of $\mathrm{Cu}$ or $\mathrm{Al}$ (Arlbrandt, 2014). Given that $\mathrm{Cu}$ is a far more valuable metal than $\mathrm{Al}$, cables with such a conductor virtually always generate higher revenues. However, paper-insulated cables come with significantly higher handling costs for recyclers, for which reason they are willing to pay significantly less for these cables than for their plastic-insulated counterparts. The environmental impact of cable recycling processes is also directly affected by the amount and type of metals that can be recycled and the generated residues for disposal (Swerea, 2012). Today, these residues, i.e., plastic or paper jacket and insulation material, are typically treated in waste incinerators including energy recovery.

\subsection{Main principles of the economic and environmental assessments}

\footnotetext{
${ }^{2}$ The implications of such different project pretenses and settings are more thoroughly explained in subsequent chapters dealing with economic and environmental assessments.
} 
It is important to note that the perspectives, and thereby also the system boundaries, are different in the economic and environmental evaluations of the scenarios. The economic assessment is done strictly from the infrastructure manager's point of view and is presented as private costs and revenues in Swedish krona (SEK). Environmental impacts of recovering cables, however, are not just caused by direct infrastructure project operations but also by indirectly influenced processes in the life-cycle of materials such as extraction, production and recycling. Hence, a broader perspective is here applied that goes beyond the on-site activities directly related to the infrastructure manager, to also include changes in affected life-cycle processes of the material flows. In principle, the environmental assessment of the different scenarios involves balancing added and avoided impacts and the result is presented as net greenhouse gas (GHG) emissions ${ }^{3}$.

In the case of waste treatment and recycling of materials, i.e., excavated masses, surface materials and extracted power cables, an avoided burden approach has been used to allocate the net climate change impacts of recycling and treatment of recovered or disposed materials (cf. Frischknecht, 2010). In this respect, excavated masses and surface materials that according to current practices in Linköping are used as landfill construction material were assumed to replace the production of corresponding volumes of earth construction material, i.e., gravel. Furthermore, separated and recycled metals (i.e., $\mathrm{Al}, \mathrm{Cu}$ and in the case of paperinsulated cables also lead $[\mathrm{Pb}]$ ) were assumed to lead to avoided environmental burdens from replaced primary metal production. Finally, the electricity and heat generated from the energy recovery of the cable recycling residues were assumed to replace conventional generation of a Nordic electricity mix and biofuel heat (Energimyndigheten, 2013).

\subsubsection{The specific assessment criteria of integrated projects}

While all activities having economic and environmental impacts were fully assessed in the twelve cable-only recovery scenarios, the evaluation of the four integrated projects only account for additional costs, revenues and environmental impacts caused by the cable recovery part. All regular project activities needed for the system upgrade were thus assumed to remain unaltered and thereby not allocated to the cable recovery.

The two selected technologies involve significantly different additional processes for extracting the obsolete cable from its subsurface location. For conventional excavation, the extra work accounted for in the scenarios involves the need to dig further down to detect, uncover and extract the obsolete cable ${ }^{4}$. Such a procedure adds extra costs and environmental burden to a regular system upgrade project in terms of more earth materials to excavate, transport to the landfill site and replace by new filler material. Adding on such a cable recovery part will also slightly extend the duration of the whole project, generating extra costs for traffic shut-offs and re-routing (Jönsson, 2014).

When it comes to Kabel-X, the situation is somewhat different given that the procedure of this technology remains indifferent to the core objective of the project, i.e., cable recovery or system upgrading. So far, Kabel-X has mainly been put to practice as a cost-efficient option to

\footnotetext{
${ }^{3}$ Given that these projects could be considered as rather non-complex with regards to energy and material flows and that most of the energy used in field operations and for material processes are fossil fuels, climate change can be seen as a first order environmental indicator (cf. Svensson et al., 2006).

${ }^{4}$ Due to historical practice, first-generation power cables are typically located at a depth of approximately 0.6 meters and are never unearthed in an ordinary system-upgrade project since the customary practice for cable installations today is about 0.4 meters depth (Swedish Standard, 2008; Jönsson, 2014). This means that at least an extra 0.2 meters of earth needs to be dug up and handled if a system upgrade project is to be integrated with urban mining.
} 
develop telecom grids ${ }^{5}$, as the created empty jacket of an obsolete cable function as channelization to install new, significantly thinner fiber optic cables. In the integrated project assessments, where the objective is to install such fiber cables, all costs and environmental impacts related to developing such a channelization in the out-of-date power cable, i.e., by extracting its metal conductor, were therefore allocated to this installation.

When it comes to the costs, revenues and environmental impacts for transporting, selling and recycling the extracted power cable, or in the case of Kabel-X the metal conductor, the assessment criteria for these integrated projects were accounted for in the same way as for the cable-only recovery scenarios. This is because all of these activities related to the handling, recycling and treatment of the extracted cable are beyond the scope of any regular system upgrade project.

\subsection{Detailed process flows and applied data sources}

The detailed process flows of the cable extraction scenarios were developed in close collaboration with two experienced infrastructure project managers at Tekniska Verken, the municipally owned utility company in Linköping, Sweden (Figure 2 and 3). All site-specific background knowledge concerns the current practices in this city, i.e., specific transportation distances, procedures for handling of excavated materials and practices for site restoration. It deserves mentioning however that Tekniska Verken's operations are very similar to how infrastructure provision is organized in other Swedish cities as well. This is because all Swedish infrastructure managers use the same national cost catalogue (EBR, 2013), containing detailed template costs as well as required machine- and/or man-hours for all sorts of project activities, to plan and budget their system upgrade projects. For these reasons, we believe the limited background knowledge that is specific for the case of Linköping to be of insignificant importance in relation to the generalizability of our results to Swedish conditions and practices.

\section{Figure 2 and Figure 3}

A cable recovery project predominantly starts with economic processes involving basic planning, arranging permits and re-routing traffic. When the working staff and machinery are established at the project site, a diesel-driven excavator is used to remove the surface material and dig the cable trench. The economic and environmental importance of these initial processes varies for the different extraction technologies. This is because Kabel-X only requires six punctiform shafts, one shaft per 100-meter cable (Furman, 2014), while conventional excavation involves digging a cable trench for the whole project length, which in our case was set at 500 meters $^{6}$.

When the desired width and depth of the cable trench has been reached, excavated masses and surface materials are either stored on-site for use as filler material (50\% in non-city center areas) or transported to a nearby landfill for reuse as construction material (50\% and $100 \%$ in non-city and city center areas, respectively). The excavator is then used with assistance from a

\footnotetext{
${ }^{5}$ The cost efficiency of Kabel-X refers to that the application of this technology avoids a significant amount of costly dig work that otherwise would have been necessary for developing such telecom grids (Furman, 2014). ${ }^{6}$ Due to fixed project start-up costs (EBR, 2013), the length of a project influences the extraction costs per meter. This is specifically important in very short repair projects (i.e., 10-50 meters), while the impact on the project cost is only of minor importance as the lengths approach 100 meters and beyond. Given that a significant share of obsolete metals in Linköping are situated in disconnected cables that are several hundred meters long (Rignell, 2014), the project length of the scenarios was set at 500 meters.
} 
blue-collar work force to uncover and extract the cable. Again, these processes are different for Kabel-X. Here, the punctiform shafts and specialized equipment are used to inject a vegetable oil between the cable core and jacket making it possible to extract only the metal conductor by the use of diesel-driven pumps and extraction machinery (Pochhacker and Furman, 2012).

Regardless of extraction technology, the on-site processes are then finalized by refilling the cable trench or punctiform shafts and restoring the surface material. Dependent on the scenario variables, the realization of these processes requires different costs and resource inputs (i.e., need for transports, machine hours and production of ballast and surface materials).

In all of the scenarios, the extracted cable/metal conductor is transported at the expense of the infrastructure manager to a metal sorting facility where they get paid based on the type and dimension of the delivered cable. From this facility, the collected cable is then transported further to a cable recycling plant involving multiple mechanical separation processes (driven by electrical power) capable of extracting close to $100 \%$ of the $\mathrm{Cu}, \mathrm{Al}$ and $\mathrm{Pb}$ (paper-insulated cables) for subsequent metal recycling (cf. Swerea, 2012). Residues from this process, i.e., paper and plastic jacket and insulation materials, are incinerated with energy recovery according to prevailing practice (Arlbrandt, 2014). The reason for not considering the option of material recycling of plastic residues from old, heterogeneous and previously buried power cables is that such recycling is yet largely limited in Sweden, mainly involving small-scale pilot tests in research programs (Boss et al., 2011).

\subsubsection{Economic data sources}

For virtually all economic processes involving planning and on-site processes, template data published in the national cost catalogue for infrastructure projects have been used (EBR, 2013). However, the project managers at Tekniska Verken provided valuable input and experience regarding exactly what processes and which data to select in the different scenarios. In addition, they provided data on some missing cost parameters in the catalogue, e.g. costs for transportation and disposal of excavated masses, as well as economic budgets for three real-life infrastructure projects, which were used to validate the scenarios. For processes beyond the knowledge of the infrastructure manager such as start-up and on-site costs for Kabel-X operations and market prices for different power cables, detailed economic data was obtained directly from the commercial actors AB Kabel-X Nordic OY (Furman, 2014) and Stena Recycling AB (Swedish recycling company).

\subsubsection{Environmental data sources}

In the environmental assessment of the different scenarios, the national catalogue for infrastructure projects (EBR, 2013) also played a central role since apart from economic figures it also contains the machine hours needed for the different on-site processes. Corresponding data regarding consumption rates of diesel and vegetable extraction oil for Kabel-X operations was retrieved directly from AB Kabel-X Nordic OY and previous pilot testing procedures in Sweden (Furman, 2014; Pochhacker and Furman, 2012). GHG emissions from these on-site processes were then calculated based on emission data for machines (i.e., diesel consumption) and extraction oil production available in the Life cycle inventory database Ecoinvent Centre (2010). For virtually all of the off-site processes involving various transports, waste management and recycling processes and primary production of materials, data for specifying energy use and related (added or avoided) GHG emissions was also obtained from this database. The only exception to this regards the metal 
recovery efficiency and electricity use of state-of-the-art cable recycling plants, data for which was collected from Swerea (2012). The main assumptions and applied economic and environmental input data are summarized in the Supplementary material for this article.

\section{Results}

\subsection{Economic viability of cable recovery by different technologies and approaches}

Extraction of subsurface cables in an urban environment is expensive and involves many different costs. When it comes to conventional excavation, the actual digging and site restoration of a cable trench typically account for $70-80 \%$ of the project budget. The remaining percentages involve mixed expenditures for project planning, land rental, traffic rerouting, cable extraction and various transports. However, in specific cases, the total cable extraction costs vary considerably, from about 800 SEK per meter to just below 400 SEK per meter (Figure 4). Two of the main scenario variables explain this difference. The geographic location of the project has a significant impact on the extraction costs, where increased need for traffic shut-offs and handling of excavated masses in city centers add an extra cost of about 200 SEK per meter to the project. Another equally important scenario variable in cableonly recovery projects is the surface material. In Swedish cities, asphalt is by far the most common pavement but in some city centers cobblestone is commonly found. Restoration of both of these types of pavement adds relatively large costs to the project, ranging from 170 (cobblestone) to 250 (asphalt) SEK per meter. Hence, with the extraction of subsurface cables solely in mind, non-city center areas covered with grass, e.g. city parks and greenbelts, offer the best economic conditions.

\section{Figure 4}

The fact that technologies such as Kabel-X only require a limited amount of excavation work make them more or less insensitive to the surface material as well as the urban location of the project (Figure 5). Apart from that such non-digging approaches drastically reduce the extraction cost to about 200 SEK per meter, the revenues that can be obtained for the relatively "pure" extracted metal conductor is about three times higher than if a whole cable is recovered and sold to recyclers. This increased income relies on the cable jacket and insulation sheaths being left behind, making the recycling of the metal much more straightforward and thus less costly for the recycling company, e.g. no gate fees and handling costs for residual plastic and paper materials.

Regardless of the applied extraction technology, our results show that projects solely aiming to recover obsolete power cables are seldom an economic option for power grid managers. For traditional excavation, the revenues are not even close to outweighing the extraction costs even in the best of cases, i.e., when a heavyweight, plastic-insulated power cable containing almost $7 \mathrm{~kg}$ of copper per meter is found in an urban park or greenbelt location. Although the economic conditions for realizing such cable recovery projects are significantly improved by Kabel-X, clear incentives only seem to occur for heavy power cables with copper conductors having at least a dimension of $3 \times 150 \mathrm{~mm}^{2}$, or in terms of copper $5 \mathrm{~kg}$ per meter (Figure 6).

\section{Figure 5}

As previously mentioned, a tentatively more viable approach to extract subsurface cables is to recover them simultaneously as the system is upgraded. For traditional excavation, however, additional costs for uncovering, extracting and transporting the out-of-date cable to recycling 
are in many cases too high to motivate such integrated projects. In principle, a break-even result can only be obtained for plastic-insulated power cables containing at least $4.5 \mathrm{~kg}$ of copper per meter (e.g. FKKJ 3x150/70 or similar). For all paper-insulated cables or cables with aluminum conductors, the revenues are simply too small to economically justify any type of recovery.

When it comes to integrated projects and Kabel-X, where the objective is to install fiber optics in the channelization provided by the empty power cable jacket, the situation is somewhat different. In such a setting, the only additional expenditure that in principle occurs for recovering the extracted metal conductor is the transportation to recyclers. Since such costs are relatively low, i.e., a few SEK per meter of cable, the integrated recovery of virtually all included power cables in this study generates an economic contribution to the project. For plastic-insulated copper cables, as an example, the net revenues for selling the extracted conductor vary from 60-280 SEK per meter depending on the cable dimension in question.

\subsection{Environmental motives for cable recovery by different technologies and approaches}

Except for when the surface material is asphalt and traditional excavation technology is used, the environmental motives for projects that solely aim to recover power cables are more encouraging (Figure 6). The restoration of asphalt pavement is very energy-intensive and causes environmental burdens that outweigh the gains even in cases of heavy power cables rich in recyclable metals. In other locations, however, when the surface material is cobblestone or grass, net avoided GHG emissions due to metal recovery through excavation can be obtained even for rather lightweight power cables. Here, an interesting observation is that when it comes to avoided GHG emissions, the recovery of aluminum cables is more rewarding than that of corresponding copper cables. Another difference compared to the economic viability of cable recovery is that the spatial location of the project is of minor importance. Instead, most of the environmental impact is caused by the excavation and other processes involving machine time such as cable extraction, transportation and recycling.

\section{Figure 6}

For Kabel-X, the environmental impact is mainly related to the production of the extraction oil and machine time (i.e., diesel consumption) needed to inject this oil into the cable and then extract the conductor. The GHG emissions are therefore similar regardless of surface material and urban location, and thus comparable in size to the impacts caused by traditional excavation in places where the surface layer is cobblestone or grass. This means that for most of the studied cases and types of power cables, there are clear environmental motives for solely extracting cables with this non-digging technology (Figure 7). Also note that the net environmental benefits obtained by the recycling of different cables (break-even lines in the figures) vary between the two extraction technologies. In terms of climate impact, extraction and treatment/recycling of the whole cable is preferable compared to just recycling the metal conductor. The reason for this is that when recycling the whole cable the lead cover will also be recovered and thus primary lead production is assumed to be avoided.

\section{Figure 7}

Similar to the economic results, the environmental performance is significantly improved for both extraction technologies when the recovery of cables is conducted as an integrated part of system upgrading. For Kabel-X, the additional environmental impact caused by such integrated recovery is related to the transportation and metal recycling process of the extracted 
conductor - impacts that are relatively small in comparison to the GHG emission savings from avoided primary metal production. Concerning traditional excavation, the environmental impacts of integrated recovery are significantly larger due to the extra machine time for uncovering, extracting and transporting the obsolete cable to the recycler. The recycling processes for the fully extracted cable are also more complex, which among other things involves the incineration of jacket and insulation residual materials generating a significant amount of GHG emissions. Still, however, integrated cable recovery by excavation leads to net avoided GHG emissions for all of the studied cases and types of power cables.

\section{Implications for local infrastructure managers}

Before discussing implications for infrastructure managers, we would like to emphasize that the assessed cost and environmental impact of the different scenarios describe typical outcomes given certain site-specific factors and project settings. As described in the method section, this assessment is based on several assumptions regarding, e.g., average replacement of excavated masses in different locations, typical depth locations of power cables, average length of infrastructure projects, and so on. Although such an approach is useful for the purpose of pin-pointing critical factors and conditions, it is also limited in the sense that it does not accurately address possible variations in costs and environmental impacts in specific real-life projects. For instance, a specific power cable might for several reasons be located at a depth of 1 meter instead of the assumed average depth of 0.6 meters, meaning that the costs for recovery in such a specific case would increase considerably. Contrary, such a particular cable might instead be located much shallower than expected, which in turn would result in minor or even no additional excavation costs for the recovery in integrated projects.

Singling out the factors that play a significant role in the scenarios allows us to point to a few key areas where solutions or changes to increase the motives for urban infrastructure mining are needed. In this respect, it is reasonable to distinguish between factors that lie inside the acting space of infrastructure managers, i.e., internal issues that are found among the actor's current operations, and what lies outside of this space, i.e., external factors that are beyond the influence of the infrastructure managers.

\subsection{Practice-related factors within the acting space of infrastructure managers}

Swedish infrastructure practices and contract agreements are not arranged with the recycling of wasted parts in mind (cf. Wallsten et al., 2013b), implying a potential for streamlining measures and improvements. Although expectations to further lower the fixed project costs at present are limited (Jönsson, 2014), there is a certain share of practice-related measures and changes that possibly are within reach for infrastructure managers.

Given that the agreement for asphalt re-paving features both as a predominant cost and environmental burden in our cable-only recovery scenarios, it seems relevant for infrastructure managers to suggest altered practices. One suggestion is that re-paving should be done only of the actual space required for the excavation work, rather than as is common now for the entire pavement width where the digging was performed. While such a changed practice alone would not make cable recovery initiatives by excavation economically viable, it would still cut the extraction cost by about $20 \%$ and the environmental impact by almost $50 \%$. For a municipality such as Linköping, with the explicit aim of being climate neutral by the year 2025 (Linköpings kommun, 2014), mitigating climate change by revising this contractual agreement might be appealing. The downside is that streets over time could become an asphalt patchwork quilt, which is neither aesthetically pleasing nor suggested for road-quality reasons. Alternatively, pavements could be gradually redesigned with e.g. split asphalt and 
cobblestone lanes, where infrastructure is to be located under the latter. Neither of these options would however seem economically favorable to the municipal owner of the street grid whose re-paving revenues would decline significantly, as they are based on a cost/area unit price mechanism (Wallsten et al., forthcoming).

Our scenarios also point to several other practice-related issues of conventional digging, which potentially could be altered to cut urban mining costs even further, also in integrated projects. Such streamlining measures involve limiting the need for replacing excavated filler materials, thus avoiding acquisition costs and transports, as well as realizing the delivery of cables to metal sorting facilities by using the trucks on the way back home for overnight parking. However, only using excavated materials for refilling the trench might, apart from mentioned storage space reasons in city centers, prove difficult due to road-quality aspects, e.g. increased risk of settling (Jönsson, 2014). Nevertheless, according to our scenarios, such streamlining measures could potentially reduce urban mining costs by an additional 10-30\% and their possible implementation will be further assessed in upcoming pilot projects.

While our results display significant barriers for urban infrastructure mining (cf. Krook et al., 2011), they also demonstrate that there are occasions when such initiatives seem economically viable. The identification of such urban mining hot spots is however often prevented by incomplete and out-of-date documentation of obsolete cables in the infrastructure managers' GIS systems (Wallsten et al., 2013b; Andersson, 2013). Updating their GIS track records and identifying more or less straightforward cases, e.g. where several heavyweight obsolete copper cables are located in the same shaft (cf. Rignell, 2014), could thus be a fruitful way to initiate urban mining activities. Such a strategy displays clear similarities with the evolution of primary production, in which the most mineral-rich deposits were mined first and then in tandem with progress in prospecting and mining technology more low-grade reservoirs became exploitable (Ayres, 1997). So far, however, GIS-based prospecting approaches have only been partly dealt with in research (Rignell, 2014) while the handling of obsolete cables remains a largely peripheral issue to most infrastructure managers (Wallsten et al., 2013b).

\subsection{External factors influencing urban infrastructure mining incentives}

Given the high costs of city excavation work in Sweden, increased urban mining practices seem to rely on non-digging technologies such as Kabel-X becoming conventional options in infrastructure provision. While such technology diffusion into already well-established markets is a challenge in itself (Geels, 2002), the applicability of Kabel-X on power cables is also related to several technical difficulties and uncertainties remaining to be addressed. One of the main challenges is that the technology at present seems especially difficult to apply on paper-insulated power cables (Pochhacker and Furman, 2012), which represent the most common type of disconnected cables in Swedish power grids.

At present, a fundamental barrier to urban infrastructure mining is too low revenues for the extracted cables. Obviously, if anticipated scenarios of gradually increasing scrap metal prices will materialize in the years to come (e.g. Sverdrup et al., 2014); we might eventually reach a breaking point when this type of unconventional resource extraction also becomes fully viable. There are, however, also other ways to influence these revenues, most of them reliant on further improvements in the recycling sector. For instance, if cable recycling processes also allowed for separation and material recycling of plastics, this would presumably increase the value of cable waste, implying higher revenues to infrastructure managers as well as improved environmental performance (Boss et al., 2011). Although the realization of such plastic recycling involves several technical and market barriers, especially when it comes to 
old, heterogeneous and previously buried power cables, ongoing research on this matter might eventually make this a viable option. Furthermore, for paper-insulated cables there are not yet any fully automated recycling processes but practice is to a large extent reliant on manual labor (Arlbrandt, 2014). This makes recycling expensive and results in even lower revenues to the infrastructure managers. The current conditions regarding paper-insulated cables are perhaps best described as a Catch-22 situation; such cables seldom end up in the recycling sector because there are no companies willing to pay well enough for them, while the reason for these low revenues partly is that such cables have not yet come in large enough quantities to motivate investments in large-scale, automated recycling facilities.

\section{Conclusions}

Under current Swedish conditions, urban infrastructure mining does not make economic sense unless it is integrated as an added value in system upgrade projects. For conventional excavation, even such integrated approaches seem hard to justify economically and rely on the cable in question being especially valuable. While not yet a fully commercialized technology, Kabel-X presents somewhat of an exception to this as the recycling of metal conductors virtually always seems to offer an economic contribution to system upgrade projects.

For infrastructure managers, facilitating recovery of subsurface cables is a multifaceted endeavor involving negotiations of contractual agreements with landowners, developing process-related streamlining measures and updating their GIS system track records to identify urban mining hot spots. It is clear however that an economically motivated urban mining practice also relies on many external factors beyond the authority of infrastructure managers. A successful market diffusion of applicable non-digging technologies, improved cable recycling processes and increased scrap metal prices signify such performance drivers. In order to further support policy-making and identify break-even points for when urban infrastructure mining could become an economically viable activity, studies addressing the implications of such external changes in policy, legislative and market conditions are strongly encouraged.

We conclude that under current practices urban infrastructure mining has more that speaks for it in environmental terms than financially. An inherent limitation of such a conclusion is however that it lets the technical means of current practice dictate what can be achieved on the societal level. This illustrates what Langdon Winner would call "reverse adaption," where societal goals are adapted to suit current technological means and practices rather than vice versa (Winner, 1977). The opposite would in our case be to have technological innovation and changes in infrastructure provision to meet defined societal goals in terms of climate change mitigation and reduced mineral resource dependence. With that said, our next quest is to assess the viability of urban mining as a way for infrastructure providers to more effectively contributing to common societal interests, motivating altered policies, regulations and provision practices.

\section{Acknowledgements}

Financial support was provided by the Swedish Research Council for Environment, Agricultural Sciences and Spatial Planning and the Swedish Innovation Agency.

\section{References}

Andersson, S. (2013). Urban mining potentials in local power grids: Hibernating Copper and Aluminium in Linköping. Master Thesis ISRN: LIU-TEMAV/MPSSD-A--13/010-SE, Linköping University. 
Arlbrandt, P. (2014). Power Plant Demolition Manager and Key Account Manager Stena Recycling AB Sweden. Personal communication.

Ayres, R.U. (1997). Metal recycling: Economic and environmental implications. Resources, Conservation and Recycling 21, 145-173.

Baccini, P. and Brunner, P.H. (2012). Metabolism of the Anthroposphere - Analysis, Evaluation, Design. The MIT Press, Massachusetts Institute of Technology, Cambridge.

Bergbäck, B. and Lohm, U. (1997). Metals in Society. In: Brune, D., Chapman, D.V., Gwynne, M.D. and Pacyna, J.M. (eds.), The Global Environment - Science, Technology and Management, Scandinavian Science, Oslo.

Boss, A., Boström, J.O., Nilsson, P.H., Farkas, A., Eriksson, A., Rasmussen, E., Svenningsson, E., Dalesjö, M. and Johansson, A. (2011). New technology for recycling of plastics from cable waste. Proceeding B.2.6 of the $8^{\text {th }}$ International Conference on Insulated Power Cables, 19-23 June, Versailles, France.

EBR (2013). Kostnadskatalog för Lokalnät 0,4-24 kV samt Optonät. EBR report KLG 1:14, Swedenergy AB [in Swedish].

Ecoinvent Centre (2010). Ecoinvent data v2.2. and Ecoinvent reports No. 1-25. Swiss Centre for Life Cycle Inventories, Dübendorf, retrieved from: www.ecoinvent.org.

Energimyndigheten (2013). Energiindikatorer 2013. ER 2013:05, Eskilstuna, Sweden [in Swedish].

Frischknecht, R. (2010). LCI modelling approaches applied on recycling of materials in view of environmental sustainability, risk perception and eco-efficiency. Int J Life Cycle Assess 15, 666-671.

Furman, D. (2014). CEO co-founder and owner at AB Kabel-X Nordic OY Finland. Personal communication. Phone: +358 94129922 , E-Mail Address: cablex.finland@gmail.com, website: http://tomas6190.wix.com/kabel-x-nordic\#

Geels, F.W. (2002). Technological transitions as evolutionary reconfiguration processes: a multi-level perspective and a case-study. Research Policy 31, 1257-1274.

Jönsson, L. (2014). Project manager and strategically responsible for the power grid development in Linköping, Sweden. Personal communication.

Krook, J., Carlsson, A., Eklund, M., Frändegård, P. and Svensson, N. (2011). Urban Mining: Hibernating Copper Stocks in Local Power Grids. Journal of Cleaner Production 19, 1052-1056.

Krook, J., Svensson, N. and Eklund, M. (2012). Landfill mining: a critical review of two decades of research. Waste Management 32, 513-520.

Krook J. and Baas, L. (2013). Getting serious about mining the technosphere: a review of recent landfill mining and urban mining research. Journal of Cleaner Production 55, 1-9.

Linköpings kommun (2014). Hållbara Linköping: CO2-neutralt Linköping 2025. Available at: http://www.linkoping.se/Miljo-halsa/Hallbara-Linkoping/

Graham, S. (2000). Introduction: cities and infrastructure networks. International Journal of Urban and Regional Research 24(1), 114-119. 
Matthews, J., Allouche, E., Sterling, R. (2015). Social cost impact assessment of pipeline infrastructure projects. Environmental Impact Assessment Review 50, 196-202.

Müller D., Wang, T., Duval, B., Graedel, T.E. (2006). Exploring the engine of anthropogenic iron cycles. PNAS 103, 16111-16116.

Pochhacker, J. and Furman, D. (2012). Kabel-X technology pilot testing project in Karlstad, Sweden, for Linköping University 9.10.2012 -12.10.2012. Technical summary report, Kabel-X Nordic OY AB.

Rignell, J. (2014). Detection of Recovery Hot-spots. A case study of Linköping's hibernated power cables. Master Thesis, Linköping University.

Sörme, L., Bergbäck, B. and Lohm, U. (2001). Century Perspective on Heavy Metal Use in Urban Areas: A Case Study in Stockholm. Water, Air and Soil Pollution 1(3-4), 197-211.

Spatari, S., Bertram, M., Gordon, B., Henderson, K. and Graedel, T.E. (2005). Twentieth-Century Copper Stocks and Flows in North America: A Dynamic Analysis. Ecological Economics 54, 37-51.

Svensson, N., Roth, L., Eklund, M. and Mårtensson, A. (2006). Environmental Relevance and Use of Energy Indicators in Environmental Management and Research. Journal of Cleaner Production 14, $134-145$.

Sverdrup, H.U., Ragnarsdottir, K.V. and Koca, D. (2014). On modelling the global copper mining rates, market supply, copper price and the end of copper reserves. Resources, Conservation and Recycling 87, 158-174.

Swedish Standard (2008). Underground installation of cables. SS 424 14 37, SIS Förlag AB, Stockholm.

Swerea (2012). Life cycle assessment of cable recycling Part I: Plastsep compared to state of the art. Confidential project report 12-001/2012, Swerea AB, Stena Recycling AB.

Tighe, S., Knight, M., Papoutsis, D., Rodriguez, V., Walker, C. (2002). User cost savings in eliminating pavement excavations through employing trenchless technologies. Canadian Journal of Civil Engineering 29, 751-761.

van Beers, D. and Graedel, T.E. (2007). Spatial Characterization of Multilevel In-use Copper and Zinc Stocks in Australia. Journal of Cleaner Production 15(8-9), 849-861.

Wendell, J. (2005). Samhällets kabelförråd och potential för ökad återvinning. Master Thesis, Linköping University [in Swedish].

Wallsten, B., Carlsson, A., Frändegård, P. and Krook, J. (2013a). To Prospect an Urban Mine Assessing the Metal Recovery Potential of Infrastructure 'Cold Spots' in Norrköping, Sweden. Journal of Cleaner Production 55, 103-111.

Wallsten, B., Johansson, N. and Krook, J. (2013b). A Cable Laid Is a Cable Played: On the Hibernation Logic Behind Urban Infrastructure Mines. Journal of Urban Technology 20(3), 85-103.

Winner, L. (1977). Autonomous Technology - Technics out-of-control as a theme in political thought. Cambridge, MA: MIT Press. 


\section{Tables}

Table 1: Technical characteristics of the included types of power cables used as a basis for calculating economic revenues and environmental impacts of recycling (based on data obtained from the Swedish recycling company Stena Recycling $A B$ ).

\begin{tabular}{|c|c|c|c|c|c|c|}
\hline $\begin{array}{l}\text { Cable } \\
\text { code }\end{array}$ & $\begin{array}{c}\text { Jacket and } \\
\text { insulation } \\
\text { material } \\
\end{array}$ & $\begin{array}{c}\text { Metal } \\
\text { conductor }\end{array}$ & $\begin{array}{c}\begin{array}{c}\text { Range of metal } \\
\text { conductor dimensions } \\
\left(\mathbf{m m}^{\mathbf{2}}\right)\end{array} \\
\end{array}$ & $\begin{array}{c}\text { Range of } \\
\text { Cu amount } \\
(\mathbf{k g} / \mathbf{m})\end{array}$ & $\begin{array}{c}\text { Range of } \\
\text { Al amount } \\
(\mathrm{kg} / \mathrm{m})\end{array}$ & $\begin{array}{c}\text { Range of } \\
\text { Pb amount } \\
(\mathbf{k g} / \mathbf{m}) \\
\end{array}$ \\
\hline FCCJ & \multirow{2}{*}{ Paper/lead } & $\mathrm{Cu}$ & \multirow{3}{*}{$3 \times 50-3 \times 240$} & $1.4-6.7$ & $\mathrm{n} / \mathrm{a}$ & $1.1-4.7^{\mathrm{b}}$ \\
\hline ACCJ & & $\mathrm{Al}$ & & $0.2-0.7$ & $0.4-1.9^{a}$ & $2.1-4.7^{b}$ \\
\hline FKKJ & \multirow{2}{*}{ PVC plastic } & $\mathrm{Cu}$ & & $1.6-6.8$ & $\mathrm{n} / \mathrm{a}$ & $\mathrm{n} / \mathrm{a}$ \\
\hline AKKJ & & $\mathrm{Al}$ & $3 \times 50-4 \times 240$ & $0.2-0.7$ & $0.5-2.5^{\mathrm{a}}$ & $\mathrm{n} / \mathrm{a}$ \\
\hline
\end{tabular}

a Also cables with $\mathrm{Al}$ conductors contain some copper in terms of an electrical copper shield.

${ }^{\mathrm{b}}$ Occurs as the main electrical shield in paper-insulated power cables. 


\section{Figure captions}

Figure 1: The four main sets of variables used for developing 16 scenarios of cable extraction from disconnected power grids. Note that surface material is not a variable in the four integrated project scenarios, where cable recovery is considered an added part to a regular infrastructure system upgrade project. The reason for that is that this cable recovery part does not add any extra costs or environmental impact to the regular project when it comes to the removal and restoration of surface materials. See text for further explanation.

Figure 2: The process flow for conventional extraction of subsurface power cables divided by main processes and data sources. Note that the economic assessment only accounts for processes generating costs and benefits for the local infrastructure provider while the environmental assessment applies a life cycle perspective. The processes included in the assessments of integrated projects involving additional costs, revenues and environmental impacts caused by cable recovery are indicated by*.

Figure 3: The process flow for extraction of subsurface power cables by Kabel-X divided by main processes and data sources. Note that the economic assessment only accounts for processes generating costs and benefits for the local infrastructure provider while the environmental assessment applies a life cycle perspective. The processes included in the assessments of integrated projects involving additional costs, revenues and environmental impacts caused by cable recovery are indicated by*.

Figure 4: Costs for cable-only and integrated recovery of obsolete power cables by conventional excavation divided by different surface materials and urban locations. Break-even lines are added for revenues that can be obtained by selling different power cables to recyclers involving different conductors and dimensions: light aluminum cable (paper insulated with aluminum conductor, e.g. ACCJ 3x50/16), heavy aluminum cable (plastic insulated with aluminum conductor, e.g. AKKJ 4x240/72), light copper cable (paper insulated with copper conductor, e.g. FCCJ 3x50/25) and heavy copper cable (plastic insulated with copper conductor, e.g. FKKJ 3x240/120).

Figure 5: Costs for cable-only and integrated recovery of the metal conductor in obsolete power cables by Kabel-X technology divided by different surface materials and urban locations. Break-even lines are added for revenues that can be obtained by selling the extracted metal conductors to recyclers involving power cables with different conductors and dimensions: light aluminum cable (paper insulated with aluminum conductor, e.g. ACCJ 3x50/16), heavy aluminum cable (plastic insulated with aluminum conductor, e.g. AKKJ 4x240/72), light copper cable (paper insulated with copper conductor, e.g. FCCJ 3x50/25) and heavy copper cable (plastic insulated with copper conductor, e.g. FKKJ 3x240/120).

Figure 6: Carbon dioxide equivalent emissions for cable-only and integrated recovery of obsolete power cables by traditional excavation divided by different surface materials and urban locations. Break-even lines are added for net avoided emissions through waste treatment and recycling of different power cables involving different conductors and dimensions: light aluminum cable (paper insulated with aluminum conductor, e.g. ACCJ 3x50), heavy aluminum cable (plastic insulated with aluminum conductor, e.g. AKKJ 4x240/72), light copper cable (paper insulated with copper conductor, e.g. FCCJ 3x50) and heavy copper cable (plastic insulated with copper conductor, e.g. FKKJ 3x240/120).

Figure 7: Carbon dioxide equivalent emissions for cable-only and integrated recovery of obsolete power cables by Kabel-X divided by different surface materials and urban locations. Break-even lines are added for net avoided emissions through recycling of different metal conductors extracted from power cables involving different conductors and dimensions: light aluminum cable (paper insulated with aluminum conductor, e.g. ACCJ 3x50), heavy aluminum cable (plastic insulated with aluminum conductor, e.g. AKKJ 4x240/72), light copper cable (paper insulated with copper conductor, e.g. FCCJ 3x50) and heavy copper cable (plastic insulated with copper conductor, e.g. FKKJ 3x240/120). 
Figures (1-7)

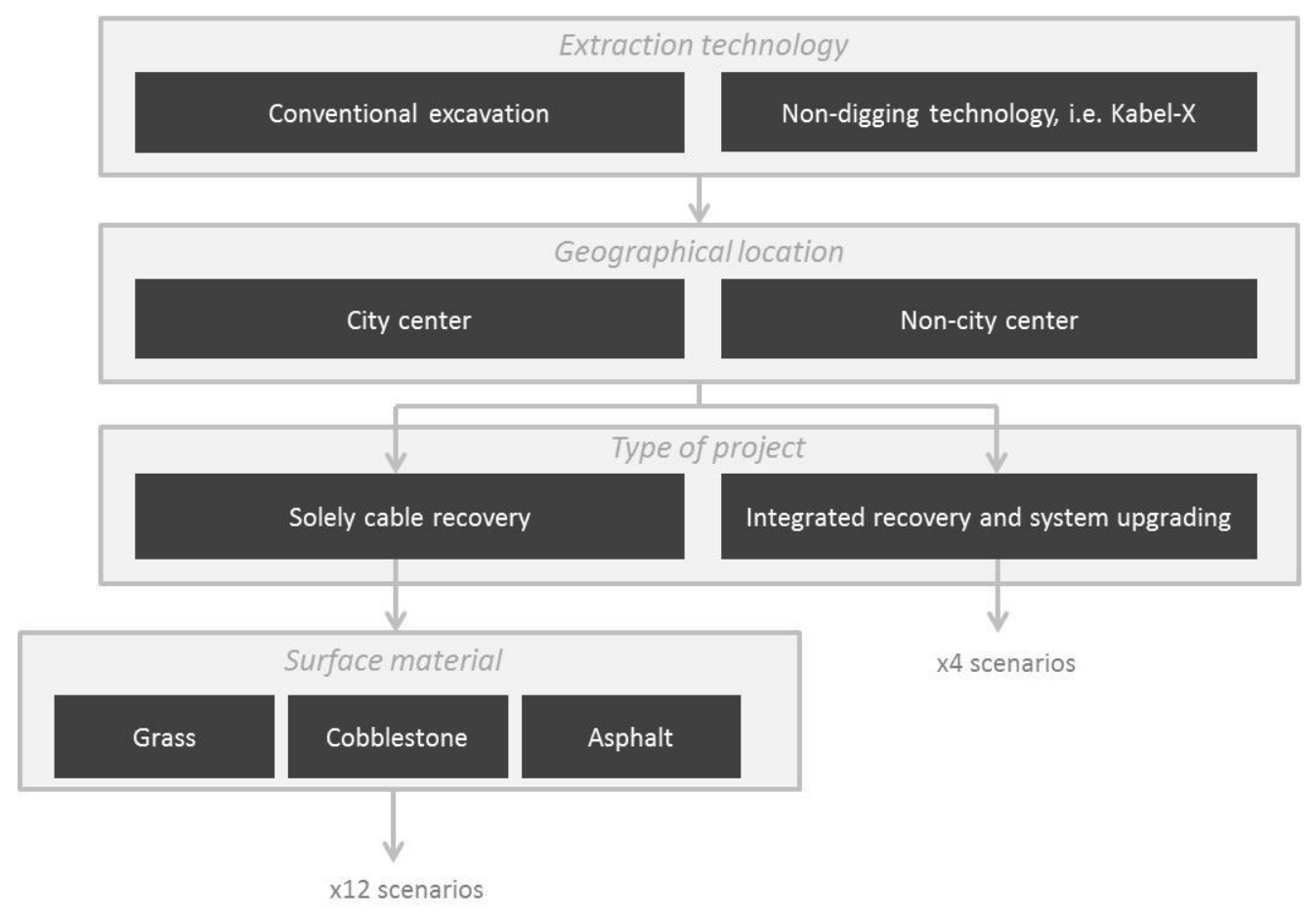

Figure 1 


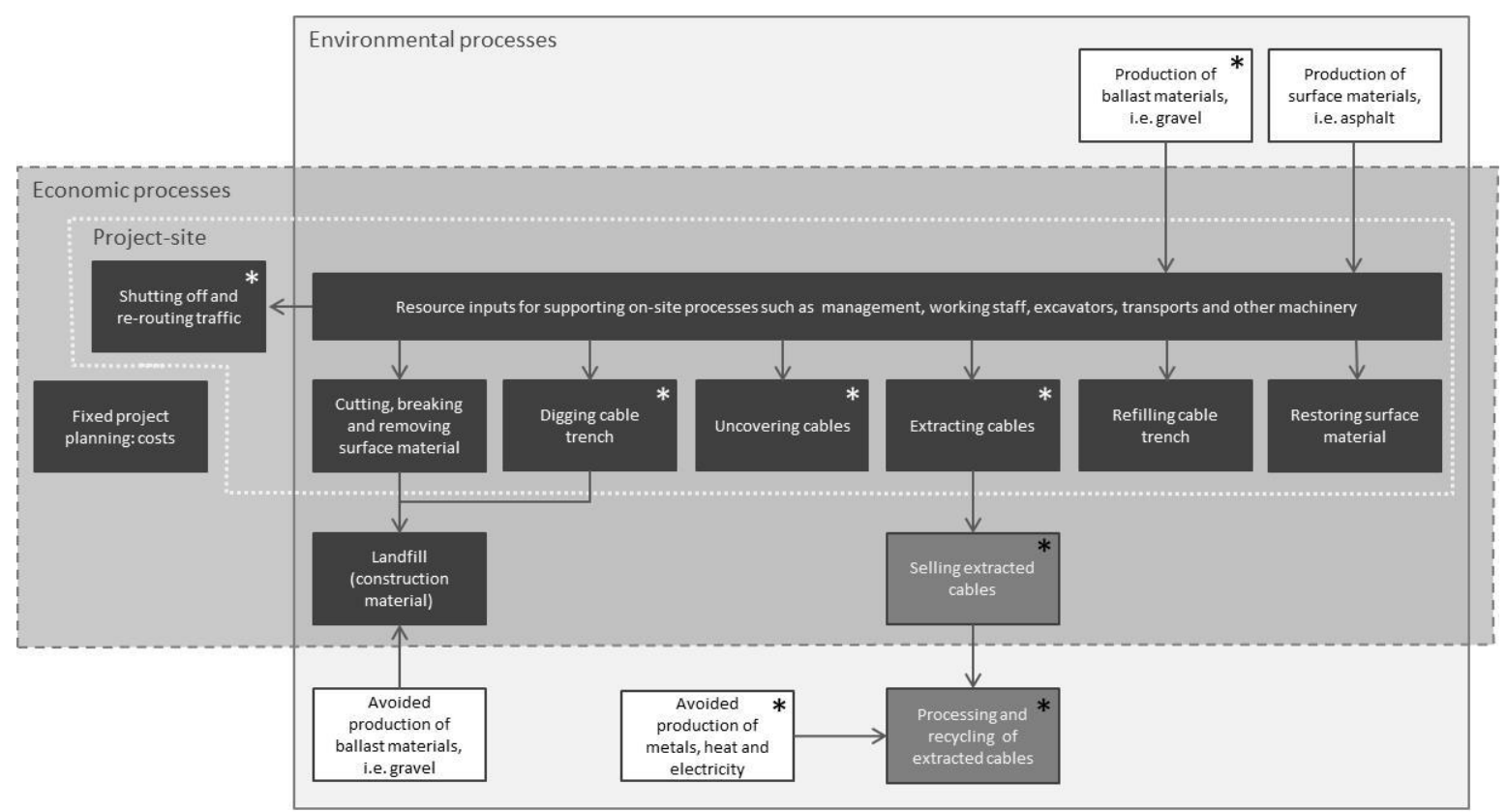

Main data sources:

EBR (2013) + Infrastructure project managers

Figure 2

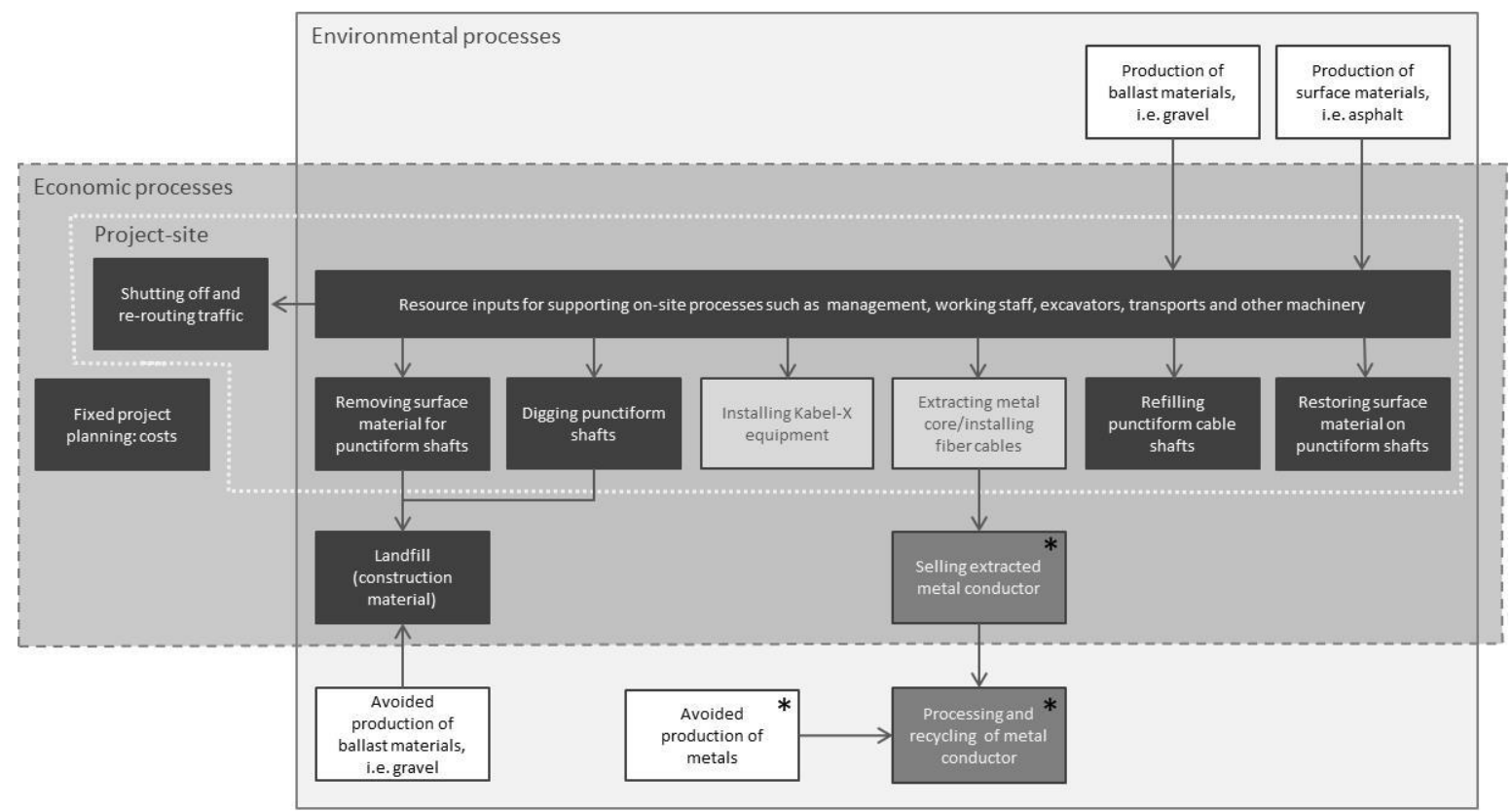

Main data sources:

EBR (2013) + Infrastructure project managers

Recycling company (Stena metall) + Swerea (2012)

Ecoinvent Life cycle inventory database

$\square$ Kabel-X provider and contractor (AB Kabel-X Nordic OY)

Figure 3 


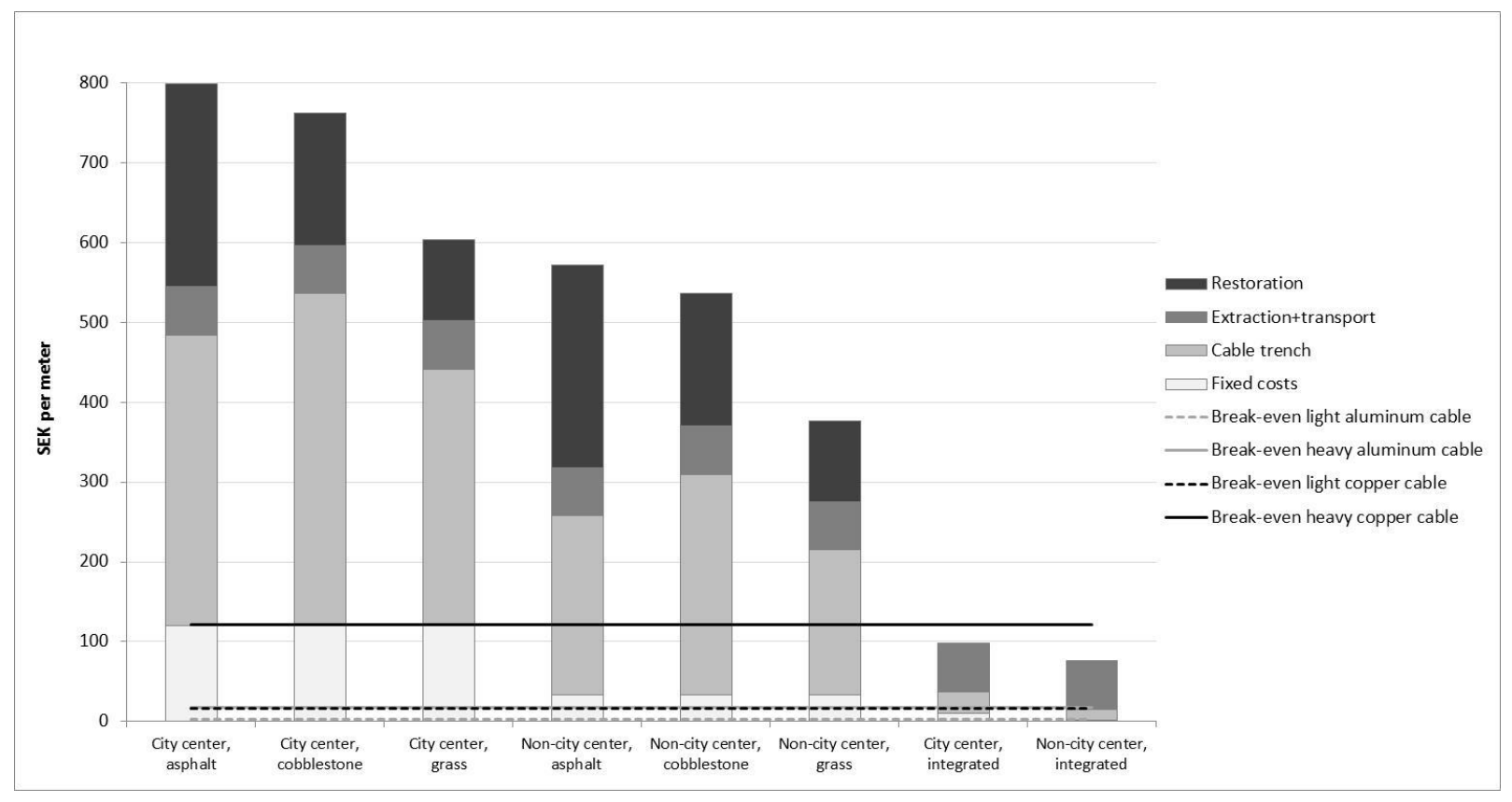

Figure 4

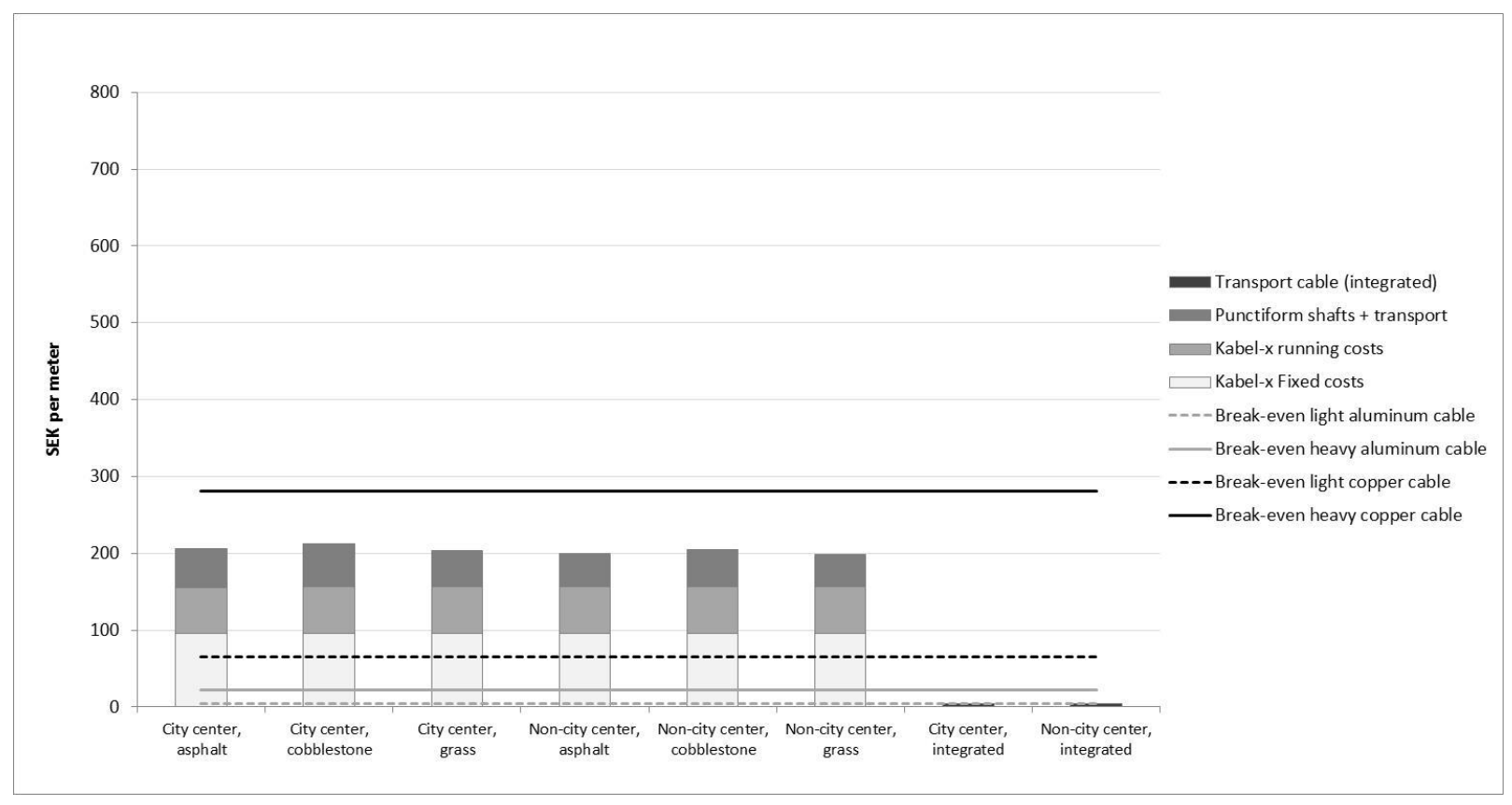

Figure 5 


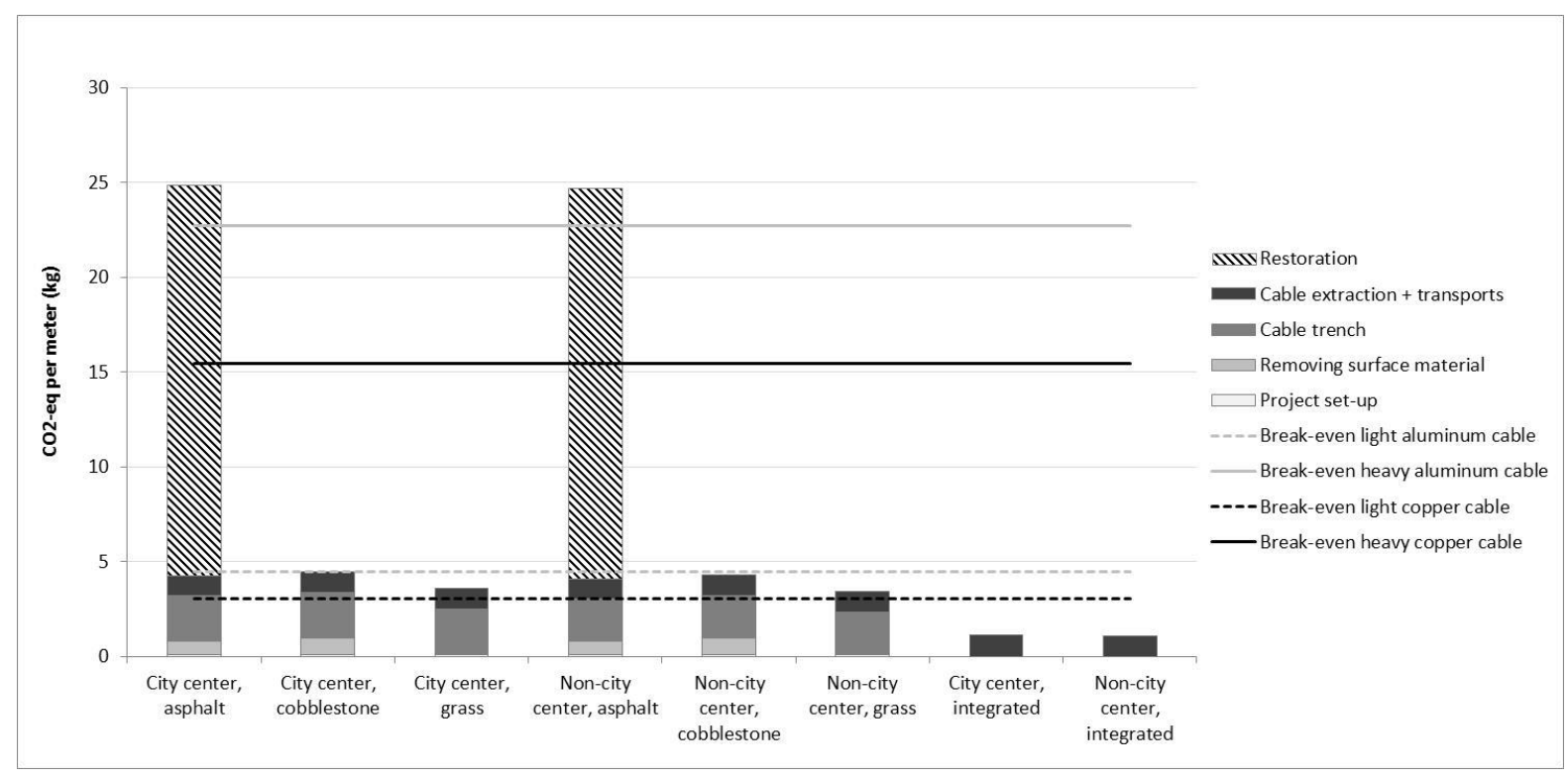

Figure 6

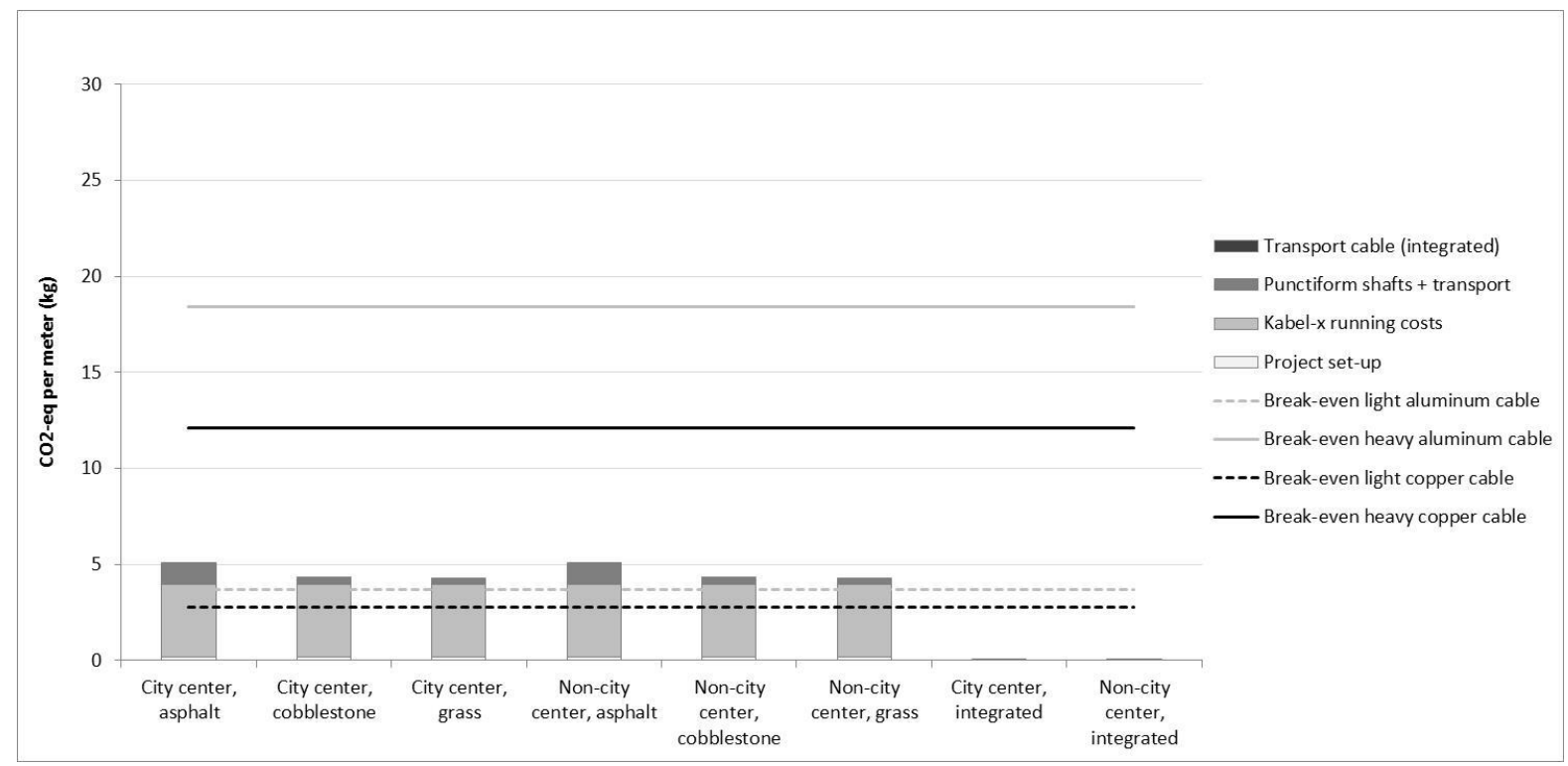

Figure 7 